COLLEGE OF AEROSPACE DOCTRINE, RESEARCH AND EDUCATION

\title{
AIR UNIVERSITY
}

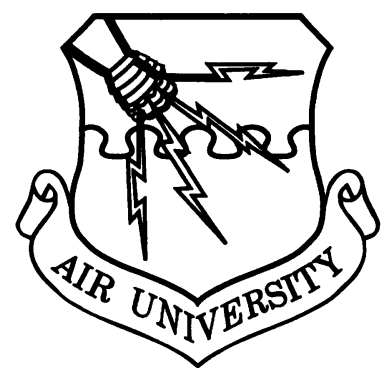

\section{Flying Reactors}

The Political Feasibility of Nuclear Power in Space

JAMES R. DOWNEY

Lieutenant Colonel, USAFR

ANTHONY M. FORESTIER

Wing Commander, RAAF

DAVID E. MiLleR

Lieutenant Colonel, USAF

CADRE Paper No. 22

Air University Press

Maxwell Air Force Base, Alabama 36112-6615

April 2005 